\title{
IN SEARCH OF THE "MECHANISMS” OF PERSISTENCE OF SUBJECTIVITY: MINIMAL SELF AND AGENCY
}

\author{
IVANA ANTON MLINAR
}

PhD in Philosophy, Professor.

National University of Cuyo.

M5502JMA Mendoza, Argentina.

CONICET (National Scientific and Technical Research Council).

C1425FQB CABA, Argentina.

E-mail:mlinariv@yahoo.es

This paper aims to analyze neuropsychiatric pathological experiences (as thought insertion and delusions of control) in which features intrinsic to subjectivity are deeply affected to the extent that the first-person perspective is lost, an essential core of the subjective condition. The distinction between the sense of agency and the sense of ownership is addressed, in particular in the context of unbidden thoughts and thought insertion. A gradualist reading of the distinction is suggested, and the problem of phenomenological adequacy of the sense of agency for thoughts is raised. Descriptive arguments are provided to show what a minimal self consists of and how it is possible that it does not get lost in extreme neuro- and psycho-pathologies, including a puzzling phenomenon such as terminal lucidity, the case in which an unexpected return of mental clarity and memory take place shortly before death in patients suffering from severe psychiatric and neurologic disorders. Based on these phenomena it is suggested that subjectivity may be underlain by some 'mechanisms' different from those usually assigned by neuroscientific models of normal brains. Finally, the challenges that emerge both for neurology and for phenomenological analysis are set out, opening new paths for the research and comprehension of subjectivity.

Key words: Cognitive sciences, minimal self, agency, psychopathologies, thought insertion, delusions of control, terminal lucidity. 


\section{В ПОИСКАХ «МЕХАНИЗМОВ» УСТОЙЧИВОСТИ СУБЬЕКТИВНОСТИ: МИНИМАЛЬНАЯ САМОСТЬ И АГЕНТНОСТЬ}

\section{ИВАНА АНТОН МЛИНАР}

Доктор философии, профессор.

Национальный университет Куйо.

М5502JMА Мендоса, Аргентина.

CONICET (Национальный научный и технический исследовательский совет).

C1425FQB Буэнос-Айрес, Аргентина.

E-mail: mlinariv@yahoo.es

В данной статье анализируются виды патологического опыта, описываемые в нейропсихиатрии (например, «чужие мысли» и бред воздействия), в которых характеристики субъективности поражаются настолько, что практически утрачивается перспектива первого лица в качестве центрального ядра субъективности. Кроме того, автор рассматривает различение между чувством деятеля и чувством принадлежности действия, в частности, в контексте навязчивых мыслей и внушений. Автор предлагает градуированную интерпретацию данного различения; вместе с тем, поднимается проблема феноменологической достоверности чувства деятеля по отношению к мыслям. Приводятся дескриптивные аргументы для иллюстрации природы минимальной формы «я». Кроме того, ставится вопрос о том, каким образом минимальное «я» не исчезает при крайних формах невропатологий и психопатологий. В частности, обсуждается случай такого загадочного явления, как предсмертная ясность ума, при котором у пациентов, страдающих тяжелыми психиатрическими и неврологическими расстройствами, незадолго до смерти неожиданно проявляется возвращение ясности сознания и памяти. Основываясь на этих явлениях, автор высказывает предположение о том, что субъективность может фундироваться на неких механизмах, отличных от тех, которые описываются в нейронауке при помощи модели нормального мозга. В заключении обсуждаются те проблемные вопросы, которые встают как перед неврологией, так и перед феноменологическим анализом, открывая новые пути для исследования и понимания человеческой субъективности.

Ключевые слова: Когнитивные науки, минимальная самость, агентность, психопатология, мысленная инсерция, мания контроля, терминальная ясность.

\section{INTRODUCTION}

After a long period of conductivism and functionalism, in which consciousness was merely tackled by the functional analysis of intentional behavior, followed by the localization and identification of particular neural correlates with functions, it seems obvious that the problem of subjectivity must necessarily consider the first-person experiential dimension. In order to study consciousness, in contrast to any other 'thing,' the phenomenological aspect must be taken into account: investigations of the 
self and experience have to be integrated if they are both to be understood (Zahavi, 2005), and therefore first-personal givenness is a primary feature of experiential life. While appealing to the physical basis of consciousness can explain some points, this attitude seems to present difficulties.

Many scientists have considered so far that research of phenomenal consciousness is inherently unreliable due to its subjective nature and is thus inappropriate for scientific research: if science only assumes third-person data, any attempt to explain what the first-person is in terms of the third-person fails to capture what it intends to explain. Yet, as Nagel (Nagel, 1974) has pointed out, a necessary requirement for any coherent reductionism is that what is to be reduced be properly understood.

A phenomenological comprehension of consciousness recognizes its subjective character, even in neuroscientists' presentations. No phenomenologist commits to the naturalization of consciousness or intentionality, if this is understood as an attempt to reduce them to non-intentional mechanisms and processes. However, many consider naturalization possible and indispensable if it is understood as the possibility of elucidation of the phenomenal character working on personal-level descriptions coming from disciplines such as psycho- and neuro-pathology, cognitive psychology, anthropology, etc., that can hold phenomenological relevance.

In this sense, the study of pathological phenomena not only can serve as a demonstration of the relevance of the phenomenological analysis of subjectivity, but also can enrich our comprehension of the nature of consciousness. Pathological cases can function as a heuristic resource: core features of subjectivity, including fundamental aspects of self-experience, can be more clearly understood through the study of their pathological disruptions.

Hence, this paper aims to analyze neuropsychiatric pathological experiencessuch as thought insertion and delusions of control-in which features proper of subjectivity are deeply affected, to the extent that they are generally described by phenomenological psychiatry as an inversion or loss of the first-person perspective, the essential core of the subjective condition. My aim is to provide descriptive arguments that: first show what a minimal self consists of so that it does not even get lost in extreme pathologies of subjectivity, in order to then present the puzzling phenomenon of terminal lucidity, in which an unexpected return of mental clarity and memory take place shortly before death in patients suffering from severe psychiatric and neurologic disorders. The acting self with a damaged brain should bring to the attention other 'mechanisms' of self-endurance. Finally, I will set out 
the challenges that emerge both for neurology and phenomenological analysis (in which that minimal self could indicate a clue) opening new paths for the research and comprehension of subjectivity.

\section{THE MINIMAL SELF}

The self has been a fundamental explanatory principle for understanding consciousness, to account for its synchronic and diachronic unity, and for that essential feature that characterizes experience: its subjectivity, its for-somebodyness, for-me-ness or mineness, its first-person character, a necessary condition for the possibility of manifestation.

Many approaches and descriptions of the self have been developed by philosophical, scientific and psychological perspectives (Neisser, 2008; Ricoeur, 1994; Taylor, 1989; Frankfurt, 1988); while some authors have denied its existence, and supported its illusory nature (Metzinger, 2003; Albahari, 2006).

Facing this plurality of features, I would like to first point out what Gallagher (2000) has called the minimal self, in an effort to arrive at primitive aspects or to the essential core of this principle, especially within the scope of pathologies in which the self may precisely be disrupted, as in the case of schizophrenia. I will introduce Gallagher's distinction between the sense of ownership and the sense of agency as two separable modalities of experience of the minimal sense of self, and will then offer some objections to this sharp distinction.

The phenomenology of these pathological experiences is a touchstone of the notion of minimal self that should lead us to the essential constituent of the agentic nature of the self, namely, intentionality, that is, a relational character. It could be shown that this minimal self seems to remain intact even under extreme disruptions of the self. Furthermore, if, as some authors suggest (de Haan \& de Bruin, 2009), this sense of agency can be present even as a potential capacity, as a Husserlian 'I can,' I therefore propose that any state of consciousness should keep its minimal sense of self, of agency.

\subsection{SENSE OF OWNERSHIP AND SENSE OF AGENCY}

Gallagher's notion of a 'minimal self' emerges from the intuition that there is a basic, immediate, and primitive 'something' that we are willing to call a self "even if all of the unessential features of self are stripped away" (Gallagher, 2000). With respect to this minimal self, he argues that it is possible to identify two separable 
modalities of experience: (1) a sense of ownership or the sense that I am the one who is undergoing an experience, and (2) a sense of agency or the sense that I am the one who is the initiator or source of the action.

In normal voluntary or willed action, the sense of ownership (SO) and the sense of agency (SA) are intimately intertwined and often indistinguishable. However, Gallagher argues that there are a number of situations in which it becomes possible to distinguish them, namely in cases of involuntary movements, unbidden thoughts, and schizophrenic experiences such as thought insertion. In these cases, according to this author, the sense of agency is lacking but the sense of ownership is retained in some form.

As some authors (de Haan \& Bruin, 2009) show, a closer examination of involuntary movements, unbidden thoughts and thought insertion reveals that the distinction between sense of ownership and sense of agency is not as clear cut and unambiguous as Gallagher proposes. Even here, agency is not completely absent. It seems that SO and SA remain intimately related and distortions of the latter also affect the former. Gallagher proposes his distinction at the level of experience as an alternative to a higher-order distinction made by other approaches at the level of attribution (Graham \& Stephens, 19941). This means that the sense of ownership and the sense of agency are originally first-order, phenomenological (nonconceptual) aspects of experience, prereflectively implicit in action (Gallagher, 2007a; 2007b). The conceptually informed higher-order attributions of ownership and agency depend on these first-order experiences.

Although Gallagher formulates a number of slightly different versions of what counts as a sense of ownership ${ }^{2}$, there are two main interpretations in his writings: one in terms of mineness, and the other in terms of kinesthesia or proprioception. This mineness is an experiential feature of the minimal self that allegedly stays constant throughout all experience and does not depend on something apart from the experience itself, since it is the most primitive form of experience that is necessarily

1 According to Graham and Stephens, ownership and agency should be primarily thought of as attributions on the basis of a reflective acknowledgment. They distinguish between the attribution of ownership; the reflective ascription of a certain action to myself, and an attribution of agency; the reflective ascription that I am the cause or author of a certain action.

2 For example, he defines it as "the sense that I am the one who is undergoing an experience" (Gallagher, 2000), as "the sense that it is I who am experiencing the movement or thought" (Gallagher, 2005), and as "the pre-reflective experience or sense that I am the subject of the movement (e.g. a kinesthetic experience of movement)" (Gallagher, 2007a). 
self-conscious. "The minimal (or core) self possesses experiential reality and is in fact identified with the first-person appearance of the experiential phenomena" (Gallagher \& Zahavi, 2008). The SO explicated as proprioception means that it involves a kind of proprioceptive awareness: "a frame of reference that applies to the lived body as perceiver and actor" (Gallagher \& Zahavi, 2008).

Concerning the sense of agency, Gallagher distinguishes between SA as a firstorder experience linked to bodily movement (Gallagher, 2007a; 2007b), and SA as a first-order experience linked to the intentional aspect of an action, a task, a goal, etc.

One prototypical example of distinguishing sense of agency from sense of ownership is the case of involuntary movement: if someone pushes me from behind I sense that it is my body that is moving. I thus have a sense of ownership. However, since I did not cause the movement, I do not have a sense of agency. Nevertheless, my reaction might already be considered agentic and provides me with a sense of agency. The influence of an outside force alone is not sufficient to compromise my sense of agency. On the contrary, to battle with the forces of nature (e.g., when sailing, swimming or climbing) is exciting exactly because we feel more capable and alive when doing so. It is precisely in those situations that we experience ourselves as active agents and have a strong sense of agency.

Other examples that Gallagher presents in favor of an SO-SA distinction are unbidden thoughts. Just like movements, thoughts can be involuntary too: they show the same lack of agency to promote the distinction between SO and SA. But the willy-nillyness of these thoughts certainly does not limit my sense of being their author. Especially if we define the sense of agency as the sense of being the source of a movement, action or thought, as Gallagher himself does (Gallagher, 2005; 2007a; 2007b); then, it is obvious that even unbidden thoughts do not at all lack this sense of agency. Gallagher actually does admit that

not only do they [unbidden thoughts] appear to be part of my stream of consciousness, but, despite the fact that I am not willing them, and may even be resisting them, they still seem to be generated within my own cognitive experience. (Gallagher, 2005)

But if those thoughts seem to be "generated within my own cognitive experience," this already reveals that the sense of agency is still firmly in place here. For the sense level, it is enough that they seem to be generated by me. I believe that the difference between unbidden and inserted thoughts is precisely that the latter are only happening in my stream of consciousness, that is, without any experience of generating them. Gallagher writes: "in the case of involuntary cognitive processes, 
I may acknowledge that I am the one who is thinking, but claim that the thoughts are not willfully generated by me" (Gallagher, 2005). This is in fact a stronger notion of SA than the description of SA in terms of being the source of a movement or thought.

In principle, just like in the case of ownership, I would welcome a gradual reading of these different notions of SA that Gallagher uses interchangeably; because it also makes clear that unbidden thoughts are no proof for a strict SO-SA distinction either. However, I doubt whether we ever experience a strong SA in terms of willful generation for thinking. When applied to movements, SA as willful generation makes sense. But when SA refers to thinking, such a description does not seem to be phenomenologically warranted.

As can be seen, most ordinary life examples do not convincingly demonstrate a strict distinction between a sense of agency and a sense of ownership.

\section{PSYCHOPATHOLOGICAL DISCRUPTIONS}

Gallagher (2005; 2007a) argues that we can understand schizophrenic experiences such as delusions of control and thought insertion as a loss of the sense of agency, while the sense of ownership remains unimpaired. Schizophrenic patients may indeed report experiences such as a loss of natural movement (the body becomes a 'machine' that needs to be 'steered'), their body moving on its own account, or alien thoughts that are in one way or another inserted in their heads (Frith, 1992, 66; Mellor, 1970, 17; Fuchs, 2000, 138 ff.). These experiences clearly lack the sense of agency that is so characteristic as to go unnoticed in 'normal' everyday life. But they report a lack of a sense of ownership as well. In fact, the hallmark of both inserted thoughts and delusions of control is that they do not feel as the patient's own thoughts and movements ${ }^{3}$. Thus, although they might feel compelled to make an attribution of ownership, this does not guarantee a corresponding sense of ownership at all.

Even recent empirical, phenomenologically informed research points in this direction warning that the most fundamental level of selfhood that appears to be affected in early schizophrenia is the automatic, prereflective articulation of the first-person perspective (Parnas, 2003). In fact, first-onset schizophrenic patients often report that although they know that it is their body that is moving and realize

3 'One man said that thoughts were being put into his mind and that they 'felt different' from his own; another said that the television and radio were responsible for different thoughts, which were 'tampered with electrically' and always felt the same way (i.e. recognisably different from his 'own')" (Spence et al., 1997). 
that it must be their thought-after all, it is going on in their mind — what is utterly disturbing about the experience is that it just does not feel that way. This objection demonstrates that Gallagher established the intactness of SO by subtly changing the target to be explained, that is, 'thought,' to 'mind.' That is, the SA is lost in certain thoughts and the SP remains at the level of consciousness or self. If, however, we insist on keeping the target the same-i.e., if we keep focusing on the inserted thought itself-it is easy to see that both SA and SO for the thought are distorted. They are precisely not 'his thoughts.' In fact, what is typical in the case of thought insertion is that schizophrenic patients report thoughts that are alien to them, instead of reporting that this thinking does not belong to them ${ }^{4}$. Such a difference between experiencing a thought and thinking could account for the different levels at which SO and SA are lacking and at which they are still intact. As Gallagher himself points out, one of the challenges in understanding thought insertion is precisely that not all thoughts feel foreign. Specific movements and thoughts are experienced as alien, but not everything and always. Thus, the relevant distinction is between specific inserted thoughts that lack both SA and SO and between the schizophrenic's own thinking, in which SA and SO are both intact.

Sass' suggestion, that the feeling of depersonalization may ultimately be due to an exacerbation of self-consciousness, a kind of ultrareflection, rather than due to a lack or loss of self-consciousness, also supports the intactness of this pre-reflective self-consciousness and intertwined condition of the SA and SO. He explains that the subject is so obsessively preoccupied with his or her experiences that they are gradually transformed and substantialized into objectlike entities, which are then experienced as alien, intrusive, involuntary and independent (Sass, 1994, 12, 38, 91, 95).

The various cases put forward by Gallagher as well as the other phenomena presented here have shown that most forms of SO already come clothed in SA. I think that this invites a gradual reading of the distinction between SO and SA rather than a categorical distinction between the two of them.

But let us consider the following: what all of my experiences have in common is the quality of mineness. At the same time, however, some of my experiences seem to be 'more mine' than others. Bodily processes such as breathing and sweating, the passive absorption of impressions, in other words, 'mere movements'-those

4 A schizophrenic patient describes inserted thoughts as "com[ing] at any moment like a gift [...] I do not dare to impart them as if they were my own" (Jaspers, 1963). 
are undeniably my experiences. But if we compare those to experiences such as swimming, thinking, and reading, we are inclined to say that these are in a sense 'even more mine.' The difference seems to lie in the fact that I brought them about and that these experiences are generated by me and are not just 'passively consumed.' In other words, the difference seems to lie in the absence or presence of agency. Following this line of thought, it is tempting to say that, whereas I am the subject of all my experiences, I am only the agent of those experiences that I have caused.

This intuition might very well be the underlying motivation for Gallagher's SO/SA distinction: being the subject of one's own experiences (the one who 'undergoes' them) should then be identified with SO and being the agent of one's own experiences (the willful generator of the action) with SA. Since agentic experiences are just a subset of all of my experiences, this clarifies why it is attractive to claim that there is an asymmetry between $\mathrm{SO}$ and SA in which SO is more fundamental than SA. The distinction between SA and SO thus seems to reflect a distinction between agency-inspired actions and mere bodily movements. The bottom line is whether it is necessary to make such a distinction. I think it is neither necessary nor desirable. In the previous paragraphs, I have tried to show that SO is a gradual phenomenon that in all but its very weakest form already includes some element of agency. If I was correct to identify the intentionality involved in even very 'passive' experiences, this renders it doubtful whether there are, phenomenologically speaking, actually such things as mere bodily movements. In fact, a large part of our everyday movements and actions are indeed not volitionally or deliberately steered, but this should not fool us into categorizing them as 'mere movements.' Rather, they exhibit an incorporated intentionality: let us consider, for example, even bodily processes like breathing, sweating or heart rate, since they can become the object of intentional steering. Or, furthermore, some movements usually considered to be unintentional and automatic are in fact learned and once required our attention.

I would thus agree that a strong SO always includes some element of agency. I would even expect that the amount of agency involved is one of the key components in determining the strength of this feeling of mineness, since I think that SA modulates SO.

I would like to propose a sketch of a broader interactive conception of agencyone that blurs the distinction between SO and SA (and also resists the temptation to privilege $\mathrm{SO}$ ) and goes beyond the distinction between SA as movement and SA as intention as well. Although I agree that there are differences in the intensity of the intentionality involved, I challenge the assumption of an intentionality- 
free sense of agency as-mere-SA as movement. I would think that it is precisely the intentionality that makes out the agentic nature. If we presuppose some form of intentionality, we can still discern gradations within SA depending on how deliberative the intentionality is. In a traditional, very strong conception, agency refers to the initiation of a priorly-intended action. If we leave out the prior intention, we get the weaker definition of agency in terms of being the 'source' of a movement or thought. I would like to go one step further and suggest that SA can also be present in the form of a potential capacity, as a Husserlian 'I $\operatorname{can}^{\text {'5 }}$ in a broader sense, that is, to experience the possibility of relating as acting without actually performing a movement or an action. The experiencing subjectivity is not only a consciousness of movement or thought, but a subjectivity capable of movement and thinking. So, my sense of agency increases the more I realize these potentialities.

Instead of understanding agency as a one-way-directed imposition of my selfinitiated will on the environment (i.e., SA as intention), I propose to conceive of agency as a relational capacity: resulting from our interactions with our environment and other agents. Agency refers to my capability to participate in the world, to interact with it and with others. As such, agency involves adjustment and receptivity as much as initiation. Participation is a two-way dynamic: it implies a constant modulation between acting and reacting and between forming and being formed, to such an extent that an easy divide between passive versus active and between internal versus external becomes questionable.

In summary, the analysis of extreme disruptions of the self, such as thought insertion and delusions of control show that alienation is not only compatible but supposes an intact SO and SA at the level of the originary experience that allows to explain the experience of an inserted or alien thought. But this then also supposes that the minimal sense of self does not get lost.

Is it possible for one to lose the minimal self? I think there is enough evidence to reject such an idea. I would like to consider some conclusions already gained in the analysis of pathologies of the self. The phenomenology of agency and ownership has disclosed that the fundamental and minimal feature of self can be conceived of as intentionality or a relational capacity. But even more fundamentally, as a potential

\footnotetext{
The bodily 'I can' is the foundation of any 'I do.' Husserl points out that there is an experience of being able to move without actually moving, because the experiencing subjectivity is embodied, what means that the body can be not only constituted, that is, experienced, but also constituting, that is, a subjectivity capable of movement.
} 
capacity, and this means, not only as a relational possibility itself but also in action as potential, that is, intentionality is such because it shapes the relational character itself by opening possibilities or a relational horizon. This first experiential level of description puts the question about the minimal self and the intentional action in its proper place, namely on a personal level.

Consequently, the minimal and fundamental sense of self seems to not be originally linked either to movements or to psychological states of consciousness. I find in this phenomenological approach an appropriate description substantiating that the minimal self does not get lost, no matter what pathologies burst into it.

\section{THE CASE OF TERMINAL LUCIDITY AND OTHER OUTLIERS: AN EVEN MORE PUZZLING PHENOMENON}

Considering the embodied and embedded condition of the self, neuropsychiatric pathologies have shown the fragility of subjectivity and how it becomes altered; but, at the same time, how, nevertheless, the core of subjectivity seems to remain.

Although psychiatric disorders are naturally correlated with brain damage in functional accounts of consciousness, in practical psychiatry and neurology, we have not said anything so far about this assumed self-brain relationship. What is usually ignored is that it results from an abstract generalization coming from the part of neuroscience and neuropsychology: both behavioral outcomes as well as brain images transformed into standard coordinate space are data averages which strictly exclude outliers. Although they are inevitable up to a certain point to reach some degree of validity in the description of the functional constitution of the organ, these criteria and their results are challenged by some cases or phenomena that force them to extend explanatory typical and normalized patterns.

In relation to extensive brain damage, for example, it could have been verified that a multidimensional sensorimotor, cognitive and socio-affective preservation was possible in a stroke patient (García et al., 2017); another case is that of a man who could efficiently serve as a civil servant although he had progressively lost roughly $75 \%$ of his brain (Feillet, Dufour \& Pelletier, 2007); a housewife with a primary cerebellar agenesis had only mild motor symptomatology (Yu, Jiang, Sun \& Zhang, 2015); multiple patients exhibited considerable restitution of language skills following early left hemispherotomy (Hertz-Pannier et al., 2002); among others. 
In this sense, another challenge for an embodied and interdisciplinary account of the self can be found in the case of terminal lucidity. The unexpected return of mental clarity and memory shortly before death in patients suffering from severe psychiatric and neurologic disorders is a frequently reported yet rarely studied phenomenon. Terminal lucidity has been reported in medical literature over the past 250 years (Nahm \& Greyson, 2009; Nahm, Greyson, Kelly \& Haraldsson, 2012) in patients suffering from brain abscesses, tumors, strokes, meningitis, dementia or Alzheimer's disease, schizophrenia, and affective disorders.

The recovery of lost memory, cognitive functions and self-identity with a deteriorated brain raises challenges both for neurology and philosophy.

Some questions for neurology could be formulated as follows:

- The neuroscience of terminal states may be more complex than has been traditionally thought.

- Seemingly irreversibly lost cognitive functions can somehow be regained. More neurologic studies are needed in terminal states.

From a philosophical perspective, the following questions arise:

- How are memory and cognitive contents retained when self-identity and cognitive abilities have been lost to be later brought back when these abilities are recovered.

- Subjectivity seems to have different 'mechanisms' to endure and to manifest than those usually assigned by neuroscientific models of normal brains.

\section{FINAL CONSIDERATIONS}

All functionalist perspectives that maintain 'the principle of localization' seem to crumble. Neural plasticity and compensation refute any hope of localizing and tying up faculties or functions to areas, specific modes or even networks. What we call 'the principle of unity,' on the contrary, appears confirmed: every part or fragmentation of the body, or every other dimension is subsequent to the unity as such, and this means that its constitution, its very notion and proper finality (as part or dimension) can only be defined from the whole that they constitute (Anton Mlinar \& López Vicchi, 2016). In this sense, the self becomes an originally unifying and agentic principle, embodied and embedded, which does not mean tied as correlated to specific neurons, regions or networks.

Outliers become, in turn, a heuristic resource, both for neuroscience and philosophy, as they force them to lead the analysis to the limits of the possibilities 
of a sense and beyond generalizing patterns. Apart from our current theories of brain plasticity, compensatory mechanisms, or cognitive reserve, there seem to be hitherto unknown forms both of functional and self-resilience.

\section{REFERENCES}

Albahari, M. (2006). Analytical Buddhism: The Two-Tiered Illusion of Self. New York: Palgrave Macmillan.

Anton Mlinar, I., \& López Vicchi, M. (2016). ¿Cómo se relacionan entre sí los niveles epistemológicos de las ciencias que estudian a la persona humana? [How Do the Epistemological Levels of the Sciences that Study the Human Person Relate to Each Other?]. In C. Vanney \& J. F. Franck (Eds.), ¿Determinismo o indeterminismo? Grandes preguntas de la ciencia a la filosofía [Determinism or Indeterminism? Great Questions from Science to Philosophy] (133-148). Rosario: Logos. (in Spanish).

De Haan, S., \& De Bruin, L. (2009). Reconstructing the Minimal Self, or How to Make Sense of Agency and Ownership. Phenomenology and the Cognitive Sciences, 9, 373-396.

Feillet, L., Dufour, H., \& Pelletier, J. (2007). Brain of a White-Collar Worker. Lancet, 370. doi:10.1016/ S0140-6736(07)61127-1.

Frankfurt, H. (1988). The Importance of What We Care About: Philosophical Essays. Cambridge: Cambridge University Press.

Frith, C. D. (1992). The Cognitive Neuropsychology of Schizophrenia. Hillsdale, NJ: Lawrence Erlbaum Associates.

Fuchs, Th. (2000). Psychopathologie von Leib und Raum. Darmstadt: Steinkopff Verlag.

Gallagher, S. (2000). Philosophical Conceptions of the Self: Implications for Cognitive Science. Trends in Cognitive Science, 4(1), 14-21.

Gallagher, S. (2005). How the Body Shapes the Mind. Oxford: Oxford University Press.

Gallagher, S. (2007a). Sense of Agency and Higher-Order Cognition: Levels of Explanation for Schizophrenia. Cognitive Semiotics, 0, 32-48.

Gallagher, S. (2007b). The Natural Philosophy of Agency. Philosophy Compass, 2, 1-11.

Gallagher, S., \& Zahavi, D. (2008). The Phenomenological Mind: An Introduction to Philosophy of Mind and Cognitive Science. London: Routledge.

García, A., Sedeño, L., Herrera Murcia, E., Couto, B., \& Ibáñez, A. (2017). A Lesion-Proof Brain? Multidimensional Sensorimotor, Cognitive and Socio-Affective Preservation Despite Extensive Damage in a Stroke Patient. Frontiers in Aging Neuroscience, Jan. 10. doi: 10.3389/ fnagi.2016.00335.

Graham, G., \& Stephens, G. L. (1994). Mind and Mine. In G. Graham \& G. L. Stephens (Eds.), Philosophical psychopathology (91-109). Cambridge: MIT Press.

Hertz-Pannier, L., Chiron, C., Jambaqué, I., Renaux-Kieffer, V., Van de Moortele, P.F., ... Delalande, O. (2002). Late Plasticity for Language in a Child's Non-Dominant Hemisphere: a Pre- and Post-Surgery fMRI Study. Brain, 125(2), 361-372. doi:10.1093/brain/awf020.

Jaspers, K. (1963). General Psychopathology (7th ed.). Manchester: Manchester University Press.

Mellor, C. S. (1970). First Rank Symptoms of Schizophrenia. British Journal of Psychiatry, 117, 15-23. Metzinger, Th. (2003). Being No One. Cambridge: Mass., MIT Press.

Nagel, Th. (1974). What Is It Like to Be a Bat? Philosophical Review, 83, 435-450.

Nahm M., \& Greyson, B. (2009). Terminal Lucidity in Patients with Chronic Schizophrenia and Dementia: a Survey of the Literature. Journal of Nervous and Mental Disease, 197, 942-944. 
Nahm, M., Greyson, B., Kelly, E. W., \& Haraldsson, E. (2012). Terminal Lucidity: a Review and a Case Collection. Archives of Gerontology and Geriatrics, 55, 138-142.

Neisser, U. (2008). Five Kinds of Self-Knowledge. Philosophical Psychology, 1, 35-59. doi: $10.1080 / 09515088808572924$

Parnas, J. (2003). Self and Schizophrenia: A Phenomenological Perspective. In T. Kircher \& A. David (Eds.), The Self in Neuroscience and Psychiatry (217-241). Cambridge: Cambridge University Press.

Ricoeur, P. (1994). Oneself as Another. Chicago: University of Chicago Press.

Sass, L. A. (1994). The Paradoxes of Delusion. London: Cornell University Press.

Spence, S. A., Brooks, D. J., Hirsch, S. R., Liddle, P. F., Meehan, J., \& Grasby, P. M. (1997). A PET Study of Voluntary Movement in Schizophrenic Patients Experiencing Passivity Phenomena (Delusions of Alien Control). Brain, 120, 1997-2011.

Taylor, Ch. (1989). Sources of the Self. The Making of the Modern Identity. Cambridge: Cambridge University Press.

Yu, F., Jiang, Q. J., Sun, X. Y., \& Zhang, R. W. (2015). A New Case of Complete Primary Cerebellar Agenesis: Clinical and Imaging Findings in a Living Patient. Brain, 138. doi:10.1093/brain/ awu239

Zahavi, D. (2005). Subjectivity and Selfhood. Investigating the First-Person Perspective. Massachusetts: Massachusetts Institute of Technology. 